AUTHOR(S): C. R. Walthers and E. M. Jenkins

Tritium Science and Technology Group

Materials Science and Technology Division

C. Mayaux and W. Obert

JET Joint Undertaking, Oxfordshire, England

SUBmitted to: Fourth Topical Meeting on Tritium Technology in Fission, Fusion, and Isotopic Applications sponsored by the Los Alamos National Laboratory

Albuquerque, New Mexico

29 September - 4 October 1991 


\section{TRITIUM RETENTION IN JET CRYOPANEL SAMPLES}

C. R. Walthers and E. M. Jenkins

Materials Science and Technology Division, Tritium Science and Technology Group Los Alamos National Laboratory Los Alamos, New Mexico 87545, USA (505) 667-1410

The possibility that tritium might exchange with water trapped in aluminum anodize cryopanels in JET prompted a test program at the Tritium Systems Test Assembly, TSTA, Los Alamos, New Mexico.

JET furnished two test pieces of cryopanel which were exposed to tritium at approximately liquid nitrogen temperature and 25 torr pressure for nearly two weeks. One specimen was removed and the retained tritium was measured. The second specimen was subjected to several increasing temperature vacuum bakeouts and the effectiveness of the bakeouts were inferred from the pressure history of the chamber. When the retained tritium in the second specimen was measured it was found that nearly $95 \%$ of the tritium, as measured in the first specimen, had been removed during the vacuum bakeouts. If the tritium retained in the cryopanel without bakeout were scaled to JET conditions according to a linear pressure time relationship, the tritium expected to become trapped in the JET cryopanels would be approximately 0.6 gram.

Testing is currently underway at TSTA which will determine the tritium retention to be expected under more realistic JET operating conditions and which will assess the effectiveness of various bake or purge schemes in removing the trapped tritium.

INTRODUCTION
C. Mayaux and W. Obert

JET Joint Undertaking

Oxfordshire, England
JET tritium operations may begin in full in 1994. It is a goal of the program to minimize the tritium inventory held up in the machine. Most surfaces will retain a monolayer or less of tritium when warmed to room temperature: thermal radiation shielding of black anodized aluminum, similar to molecular sieve, may retain more tritium at $77 \mathrm{~K}$ but will release most tritium when warmed to room temperature. Water trapped in black anodize is very difficult to remove: generally vacuum baking at temperatures in excess of $300^{\circ} \mathrm{C}$ is required. Even a brief exposure to atmosphere is sufficient to load black anodize with water. Tritium readily exchanges with hydrogen when exposed to hydrogen compounds and this exchange is catalyzed by the radiological nature of tritium so that a tritium/hydrogen exchange may be much more rapid than a deuterium/hydrogen exchange. In preliminary tests, no exchange was detected between trapped water and deuterium (see Ref. 1). Both factors combined, the quantity of water trapped in the black anodize and the tendency of tritium to exchange with hydrogen in compounds, present a potential problem.

How much tritium becomes bound up in water form in the black anodize structure and what is needed to recover it? The program was run in two phases: the first, performed in August and September of 1990, involved a very severe tritium exposure to ieam if there was a problem; 
the second, to be run in the coming months, will more carefully quantify the extent of tritium retention for a number of exposures. This report describes the first phase of testing in which the existence of the problem was established.

\section{TEST APPARATUS}

Figure 1 shows the main components of the test apparatus for the Phase I tests. A vacuum jacketed environmental chamber, having a volume of approximately 6.6 liters, was installed in a glovebox in the main experimental hall at the Tritium Systems Test Assembly at Los Alamos. The wall of the environmental chambers was wrapped with a $6 \mathrm{~mm}$ dia. tube through which nitrogen could be passed. Liquid nitrogen was passed through the tube for cooling; 100 psig N2 gas was heated prior to flowing through the tube for elevated temperatures. With this arrangement, specimen temperatures from 175 to $+300^{\circ} \mathrm{C}$ could be achieved. Thermocouples were attached to the specimens and to the chamber wall. Pressure within the chamber was read with a Convectron gage and a 0-1000 torr Baratron gauge.

Tritium was stored on a zirconuimcobalt getter bed: heating the bed drove the tritium off and into the chamber until the desired pressure was achieved. At the conclusion of exposure, the tritium was replaced on the bed at room temperature. When impurities blanketed the bed, helium was added to the chamber as a carrier gas. A Metal Bellows pump then circulated batches of the gas mix through the getter bed until the tritium was removed.

A turbopump was used for pumping out the chambers when filled with an inert gas (nitrogen or helium) and for removal of outgassed products during bakeout. A residual gas analyzer was used to determine what gasses were out gassed during bakeout and to see when carrier gas pumped through the getter bed was free of tritium.

Leaching solution was prepared from $10 \%$ concentrated hydrochloric acid and 90\% distilled water in a procedure similar to that described in Ref. (2). For an absolute determination of retained tritium, the specimen was removed from the environmental chamber and placed quickly into a 1 liter container of this solution. The container was sealed and removed from the glovebox for analysis using a liquid scintillation counter.

A mass flowmeter, with a range of 0 $10 \mathrm{sccm}$, was used to calibrate the flow/pressure characteristics of the environmental chamber prior to the exposure. This flowmeter, not shown in fig. 1 , was connected to the chamber and the flow/pressure relationship of the chamber, connecting lines and turbopump was determined with gaseous nitrogen. This relationship was used to determine relative outgassing rates at various temperatures during specimen bakeouts. No attempt was made to determine precise outgassing rates because the tritium retained before and after bakeout was measured with good accuracy using the leach sample/scintillation counters.

\section{TEST METHCD}

The approach followed was to expose two samples to tritium, remove one and determine retained tritium by measuring concentration in a leach bath. The second specimen was subjected to increasing temperature vacuum bakeouts and the relative effectiveness of the bakeout was determined from the pressure time histories. When the second specimen was analyzed, using the leach bath scintillation counter method, the effectiveness of all the bakeouts was evident.

The two specimens, approximately 100 $\mathrm{cm}^{2}$ each, were washed with demineralized water and allowed to air dry for several 
days. This assured that the anodize was completely loaded with water. The specimens were placed in the environmental chamber which was sealed and evacuated by the turbopump. Tritium was introduced to the chamber by heating the getter bed: the chamber was chilled and conditions of $-175 \mathrm{C}$ and 20 torr tritium pressure were maintained for two weeks.

Several days were required to transfer tritium back to the getter bed because of impurities which tend to blanket the getter and reduce pumping. A batch method was used whereby helium was introduced into the chamber, then expanded into the getter bed and pump shown in fig. 1. The chamber was isolated and the helium/tritium mixture was circulated over the getter until the tritium content was sufficiently small so that the helium carrier gas could be pumped away. This procedure had to be followed many times before the chamber could be opened and one specimer. removed.

Several vacuum bakeouts were performed on the remaining specimen to nominal levels of $100^{\circ} \mathrm{C}, 200^{\circ} \mathrm{C}$ and $280^{\circ} \mathrm{C}$. During bakeout the outgassed products were sampled with the residual gas analyzer. By the conclusion of the last bakeout, the specimen remaining had been under vacuum levels on average in the micron range for 9 days. The specimen was removed from the chamber and placed in the one liter leachate bath. A control bath was opened to the glovebox atmosphere for the same time duration. This concluded the experiment.

\section{RESULT}

The two specimens were placed in leachate baths immediately upon removal from the chamber and samples of the leachate were removed and diluted for scintillation counting until a constant stable reading was attained. This required 11 days for specimen 1 and 4 days for specimen 2. The stabilized tritium levels leached out of the samples were:

Specimen \#1 (no bakeout) $10.3 \mathrm{Ci}$

Specimen \#2 $\left(100,200,280^{\circ} \mathrm{C}\right.$ bakeouts) $1.42 \mathrm{Ci}$

These resulted from $100 \mathrm{~cm}^{2}$ specimens. On a square meter basis the tritium retention for the before and after bakeout specimens as determined from the leachate is:
Specimen \#1
$1.03 \times 10^{3} \mathrm{Ci} / \mathrm{m}^{2}$
Specimen \#2
x $10^{2} \mathrm{Ci} / \mathrm{m}^{2}$
(before bakeout)
(after bakeout) 1.42

Figure 2 shows the relative outgassing rate for the three bakeouts. The approximate contribution of each bakeout to the total measured for the three bakeouts is:

$$
\begin{array}{ll}
100^{\circ} \mathrm{C} & 62.4 \% \\
200^{\circ} \mathrm{C} & 24.0 \% \\
280^{\circ} \mathrm{C} & 13.6 \%
\end{array}
$$

That is, of the water vapor removed during bakeout, the amount removed at each temperature was in this proportion. The amount pumped away before baking began and that not removed during the three bakeouts is not accounted for.

The majority of the outgassed products as indicated by the residual gas analysis was water vapor. Of the water vapor peaks measured, approximately $7 \%$ could be attributed to tritiated water vapor.

\section{CONCLUSION AND FURTHER WORK}

The tritium retenticn measured in this experiment suggests a potential problem. The JET has approximately $200 \mathrm{~m}^{2}$ of the tested material. Therefore, grams or tens of grams of tritium could become held up in the cryopanels as a result of a tritium exposures like the one tested here. 
However the projected JET pressure exposure duration is 20 times less than used here so if hold up scales directly we could expect tritium retention on the order of $6000 \mathrm{Ci}$ or $0.6 \mathrm{~g}$ in the absence of bakeout. Whether tritium retention scales as the product of pressure duration will be measured in the Phase 2 tests presently underway at TSTA. The Phase 2 will employ an improved environmental chamber suited to outgassing measurements and having improved pressure instrumentation and higher bakeout capability.

\section{REFERENCES}

1. W. Obert; draft, " Tritium Retention and Water Tritiation Tests on Samples of the Black Anodized Cryopump Surfaces of the Jet Cryopumps", internal document JET Joint Undertaking, Oxfordshire, England.

\section{Rion Causey and Roland Jalbert,} "Tritium Retention on TFTR Neutral Beam Components", LA-UR-88-3956.

\section{DISCLAIMER}

Thi: report was prepared as an account of work sponsored by an agency of the United States Government. Neither the United States Governmeni nor any agency thireof, nor any of their employees, makes any warranty, express or implied, or assumes any legal liability or responsibility for the accuracy, completeness, or usefulness of any information, apparatus, product, or process disclosed, or represents that its use would not infringe privately owned rights. Reference herein to any specific commercial product, process, or service by trade name, trademark, manufacturer, or otherwise does not necessarily constitute or imply its endorsement, recommendation, or favoring by the United States Government or any agency thereof. The views and opinions of authors expressed herein do not necessarily state or reflect those of the United States Government or any agency thereof. 


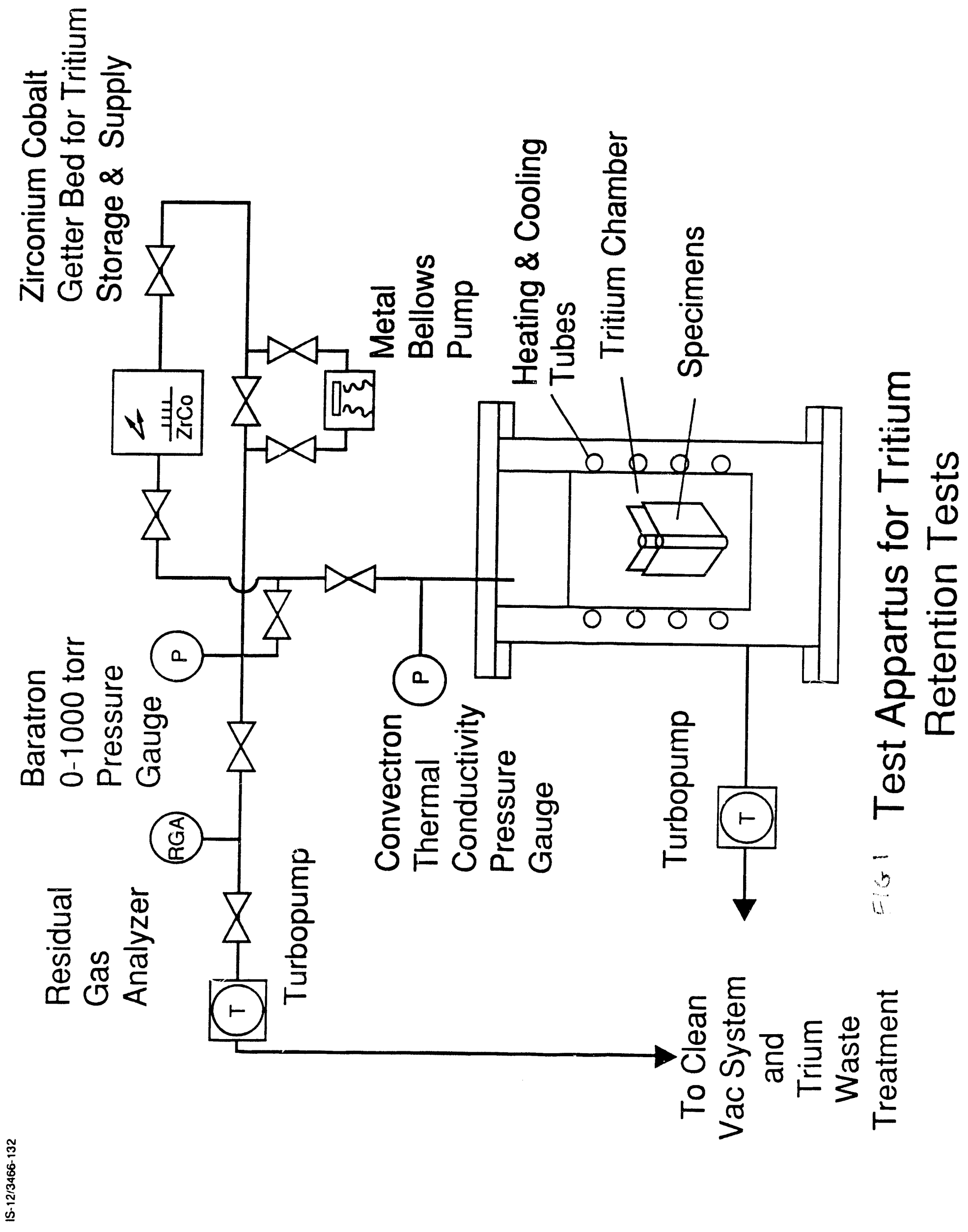




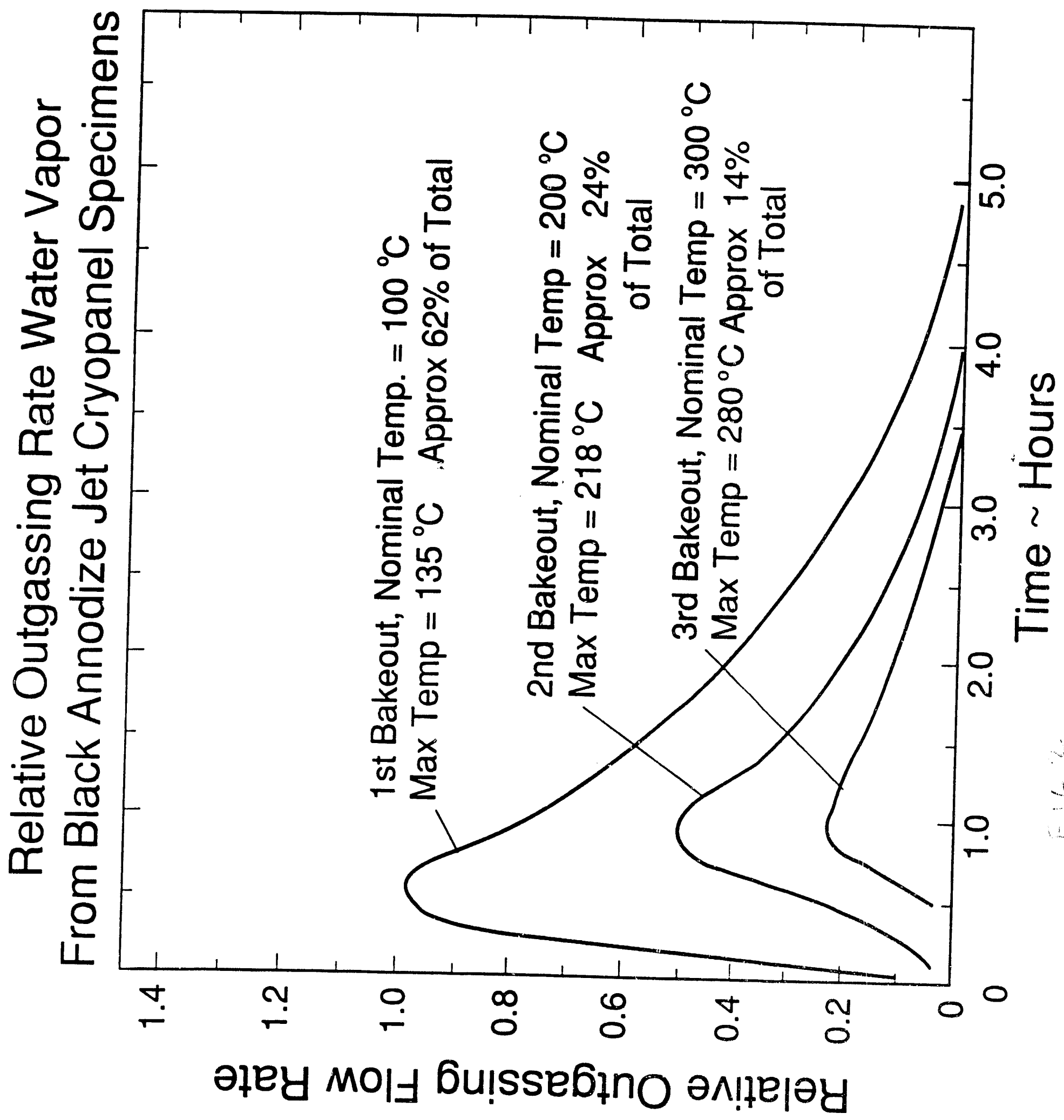



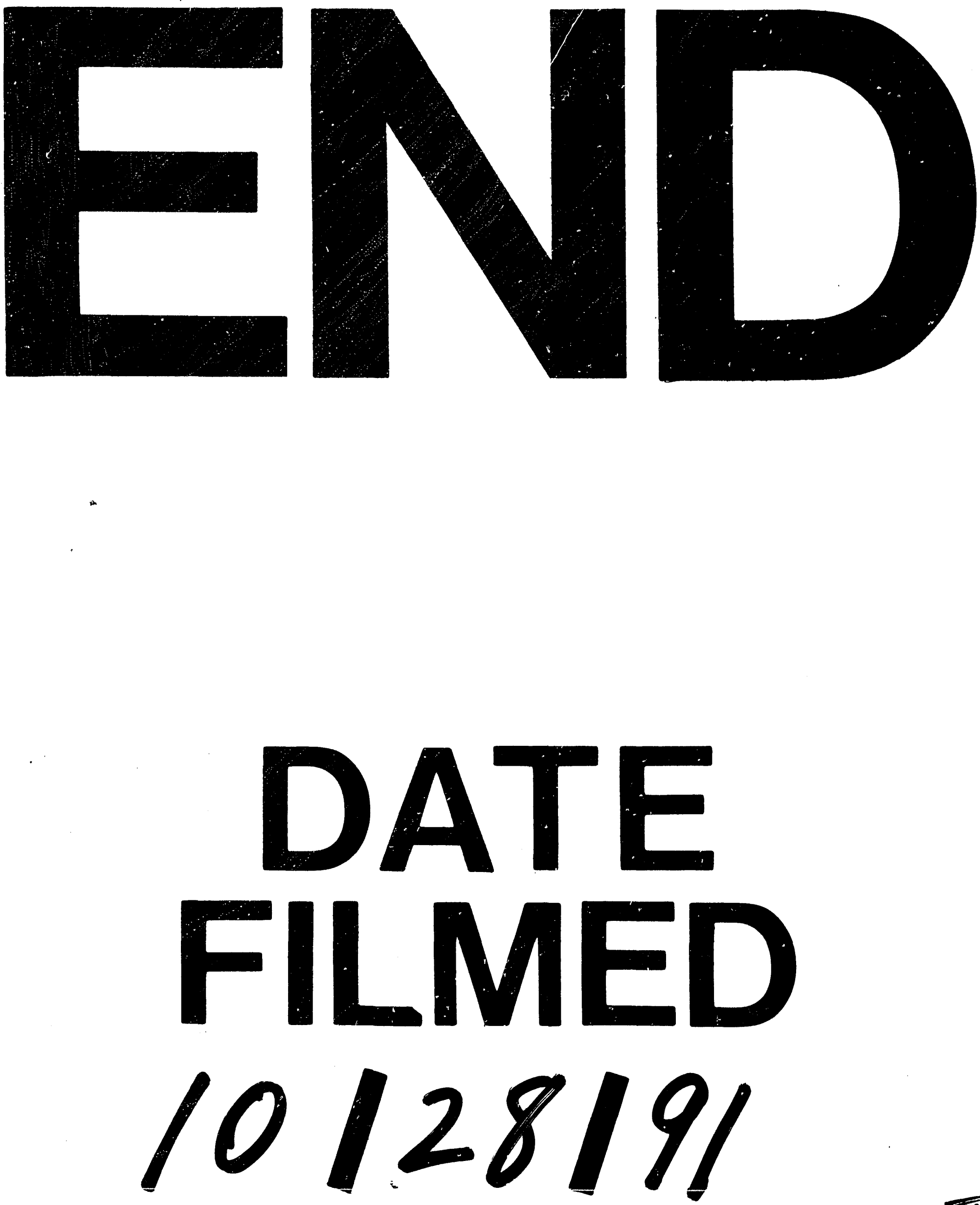
